УДК 1:294.3

ББК 86.35

DOI $10.31554 / 2222-9175-2018-30-167-176$

\title{
А. Ц. Гупгенова
}

\section{ВПИЯНИЕ ТИБЕТОЯЗЫЧНЫХ ИСТОРИКО-ФИПОСОФСКИХ ТЕКСТОВ НА РАЗВИТИЕ БУДДИЗМА В ТИБЕТЕ И ЦЕНТРАПЬНОЙ АЗИИ}

Представлен анализ факторов и условий, повлиявших на развитие буддизма в Тибете и странах Центральной Азии. Раскрывается генезис жанра сиддханта, сыгравшего значительную роль не только в распространении буддизма, но и в формировании мировоззрения, социально-политического уклада и культуры народов этих стран.

Ключевые слова: сиддханта, Гелугпа, древнеиндийский буддизм, дубта.

\section{A. Ts. Gulgenova}

\section{INFLUENCE OF TIBETAN HISTORICAL AND PHILOSOPHIC TEXTS ON THE DEVELOPMENT OF BUDDHISM IN TIBET AND CENTRAL ASIA}

In this article the author offers an analysis of factors and conditions influencing the development of Buddhism in Tibet and Central Asian countries. It reveals genesis of siddhānta genre, which played a significant role not only in dissemination of Buddhism, but also in shaping of worldview, sociopolitical setting and culture of the peoples of these countries.

Keywords: siddhānta, Gelugpa, ancient Indian Buddhism, dubta.

B Тибете период XI-XII вв. отмечен возникновением уникального жанра историко-философской литературы, который посвящен истории становления и развития различных религиозно-философских учений, школ и сект. Этот жанр широко известен тибетским, монгольским и бурятским буддийским ученым под названием «дубта» (тиб. Grub-mtha'), а среди европейских буддологов более популярен под названием «сиддханта» в санскритском варианте.

Термин «Grub-mtha'» («дубта») в переводе с тибетского языка означает «разряд учения», «результат решения», «постановление», «сформировавшееся учение», «установившийся взгляд» и соответствует санскритскому термину «сиддханта» в значении «сформировав- шееся учение», под которым понимается история религиозно-философских учений, школ и сект буддизма в странах Азии [Хадалов 1962: 40]. В санскритском значении слово «siddha» означает «доказанное», т. е. утверждение, полученное из авторитетных источников (тиб. lung) и посредством логического рассуждения (тиб. rigs). Санскритский термин «anta» означает «окончательно», т. е. «то, что не выходит за эти пределы [Хундаев 2009: 79].

Тибетский жанр сиддханта возник в процессе систематизации и синкретизации буддийского учения и формирования школьной буддийской системы. Развитие жанра сиддханта во многом связано с герменевтической проблемой согласования буддийских учений, а также перевод-

ГУПГЕНОВА Арюна Цыденжаповна - доктор философских наук, консультант информационно-аналитического отдела Министерства социальной защиты населения Республики Бурятия (Улан-Удэ, Россия). E-mail: agulgenova@mail.ru. 
ческой, комментаторской и миссионерской деятельностью тибетских монахов.

Значительное количество работ по истории философии приходится на поздний период развития тибетской религиозно-философской традиции, а именно на период формирования схоластической литературы. С. П. Нестеркин справедливо отмечает, что такая востребованность сравнительных исследований была вызвана как разнообразием философских доктрин, возникших на тибетской почве, так и разнообразием интерпретаций индийского философского наследия в этих школах и направлений тибетской мысли [Нестеркин 2014: 11], став, таким образом, одной из причин возникновения в средневековом Тибете уникального жанра сиддханта.

В основу исследований тибетских авторов легли наиболее ранние индийские трактаты, в которых проводится сравнительный анализ философских воззрений различных школ и направлений буддизма: «Byig-gi-bshes-gnyen. gZhun-glugskyi-bye-brag-pa'i-‘khor-lo» (санскр. «Caмаявадхопарачаначакра», «Колесо, утверждающее различие главных мнений») Васумитры и «lCang-skya. Grub-pa'i mtha'i-rnam-par-bzhag-pa-gsal-bar-bshadpa-thub-bstan-lhun-po'i-mdzes-rgyan»" (санскр. «Таркаджвала», «Ясное объяснение философских систем "Прекрасное украшение Меру Ученика Муни”») Бхававивеки (санскр. Бхавья, тиб. Legs-ldan). В сочинении Васумитры, которое переводится «Колесо, утверждающее различие главных мнений», содержатся сведения о различиях взглядов 18 древнеиндийских буддийских школ. Она признается В. П. Васильевым источником «для более подробных и ученых исследований постепенного развития буддизма» [Васильев 1869: 258]. Однако наиболее значимым для махаянской мысли стал второй источник - «Таркаджвала» Бхавьи, который представляет собой объемное сочинение с подробной характеристикой существовавших в Древней Индии различных мировоззрений, насчитывавших свыше 360 разных направлений.
По мнению С. П. Нестеркина, это сочинение появилось в результате необходимости систематизации не только воззрений хинаяны, но и махаяны, поскольку к тому времени уже появились разночтения в понимании традиции махаяны (йогачаринская и мадхьямиковская), а также различные понимания мадхьямики [Нестеркин 2014: 11]. Он также отмечает, что в ее интерпретации Бхававивека оппонировал Буддхапалите, и эти две интерпретации позднее получили наименования мадхьямика-сватантрика и мадхьямика-прасангика. Предположительно, именно эти сочинения послужили непосредственными источниками возникновения жанра сиддханты в Тибете.

В настоящее время в науке существует несколько версий причин возникновения и генезиса жанра сиддханта. Одну из гипотез предложили Д. Козорт и Г. Престон, которые отождествили сиддханту с литературой типа «lta-ba» («тава») [Cozort, Preston 2004]. Согласно их версии «Man-ngag-lta-ba'i-phreng-ba» («Гирлянда воззрений: Наставление») Падмасамбхавы стала первым трактатом в этом стиле. Также, по их мнению, в период VIIIIX вв. были написаны еще два сочинения о философских системах, заложившие основы для появления сиддханты: «Ltaba-rim-pa-bshad-pa» («Объяснение этапов воззрений») знаменитого тибетского переводчика, ученика Шантаракшиты и Падмасамбхавы Кавы Палцэга (тиб. sKaba-dpal-brtsegs), и «Lta-ba'i-khyad-par» («Различие воззрений») выдающегося тибетского переводчика, ученика Падмасамбхавы, участвовавшего в переводе более 200 текстов, Еше Дэ (тиб. Ye-shes-sde / sna-nam-Ye-shes-sde / zhang-gi-bhan-dheYe-shes-sde). Самой ранней из известных и сохранившихся сиддхант считается «Grub-mtha'-so-so'i-bzhed-tshul-gzhunggsal-bar-ston-pa-chos-'byung-grub-mtha'chen-po-bstan-pa'i-sgron-me» («Ясное изложение соответствующих взглядов и положений философских систем: “Светоч учения, Великий трактат по философским системам [в контексте] Истории Дхармы"»), написанная нигмапинцем 
Шераб Одом (тиб. Shes-rab-'od, 11661244). Это дает право представить версию о том, что жанр сиддханта впервые возник в недрах нигмапинской традиции.

Согласно второй версии, изложенной учеником Кунчена Жамьяна Шадпы знаменитым историком Сумба-кхамбо Ешей Балджором в трактате «Пагсам-Чжонсан», первая сиддханта была написана в Тибете Атишей на рубеже X-XI вв. В ней Атиша изложил историю школ современной ему Индии - вайбхашики, саутрантики, йогочары, сватантрики и прасангики. Отличительной чертой его сиддханты стало то, что в ней представлены школы в иной последовательности, нежели у его предшественников [Островская 2002: 43 ]. К сожалению, названия этой сиддханты и содержание ее неизвестны. Тем не менее японский буддолог Кацуми Мимаки убежден, что первые сиддханты стали разрабатываться в XII-XIV вв. в главных кадампинских центрах - Сангпу (тиб. gSang-pu) и Нартанг (тиб. sNar-thang) [Katsumi 1982]. Таким образом, в соответствии с этой гипотезой происхождение жанра сиддханта относится примерно к XI-XII вв. и принадлежит школе кадампа.

Третья гипотеза основывается на мнении А. И. Вострикова о том, что жанр историко-философской литературы возник в рамках обширного класса тибетской исторической литературы, называемой «chos-'byung» (чойнчжун, «история религии или доктрины»). Согласно концепции А. И. Вострикова, этот класс объединяет и сочинения по истории религии, и «общие исторические труды сводного характера, в которых изложение истории религии дается вместе с изложением светской истории страны» [Востриков 1982: 89]. По своему содержанию «истории религии» - чойнчжуны достаточно разнообразны, поскольку посвящены либо истории Тибета и буддизма в Тибете, либо истории распространения буддизма в Китае, Индии, Монголии, либо изложению светской и духовной истории всех или некоторых из народов этих стран вместе. Кроме того, в этот же класс входят произведения, посвящен- ные истории распространения буддизма в определенной области или местности, а также сочинения, излагающие историю того или иного буддийского течения или монастырской школы. В свою очередь, в науке остается вопрос о самом происхождении жанра чойнчжун. По мнению Леонардо Ван дер Кипа, самая ранняя работа, исполненная в этом жанре, принадлежит авторству нигмапинского мастера Ронзом Чойкьи Зангпо, жившему в XI в. Она цитируется в сочинении Дульзина Кьенраба Гьяцо «Sangs-rgyas-bstan-pa'ichos-byung-dris-lan-nor-bu'i-phreng-ba» [«Ответы на вопросы по истории буддийского учения: “Драгоценная гирлянда”»] [Tibetan literature 1996: 43]. Таким образом, можно предположить нигмапинское происхождение жанра сиддханта.

Согласно мнению Е. А. Островскоймладшей, которая убеждена в создании жанра чойнчжун сакьяпинцами [Пубаев 1980: 243], самый ранний чойнчжун написан сакьяпинцем Соднам Цзэмо (1142-1182) в 1168 г. Однако возможны и более ранние сочинения представителей этой школы. Д. Джексон в своей статье «Два трактата по grub-mtha' - одна утерянная и одна фальсифицированная» приводит название одной из сакьяпинских сиддхант - «Grub-mtha'-rnam-'byed / grub-mtha'i-dbye-ba» («Различие / Классификация философских систем») Сакья Пандиты (1182-1251) [Jackson 1985]. Тибетец ссылается на нее в своих трудах, таких как «Tshad-ma-rigs-pa’i-gter-gyirang-'grel» («Автокомментарий к “Сокровищу логики и эпистемологии”»), «Mkhas-rnams- 'jug-pa'i-sgo» («Освещение мысли муни») и «Thub-pa'i-dgongsgsal» («Врата мудрецов»). К сожалению, эта сиддханта была утеряна предположительно в середине XIII в.

Таковы гипотезы генезиса жанра сиддханта. Между тем все вышеизложенные версии связаны с герменевтической проблемой согласования буддийских учений, а также переводческой, комментаторской и миссионерской деятельностью. Интерпретация онтологической проблематики, содержащейся в работах 
Арьядевы, Буддхапалиты, Бхавьи, Чандракирти, Шантаракшиты и других древнеиндийских мыслителей, в тибетском буддизме велась в рамках литературы по мадхьямаке, выработанной в рамках основных школ тибетского буддизма. Однако различия в интерпретации базовых текстов индийских авторов у основных представителей этих школ носили принципиальный характер.

Обращаясь к предпосылкам написания сиддхант, нельзя не затронуть социально-политическую сторону того времени, которая играла немалую роль в развитии духовной и культурной жизни общества. Масштабные переустройства политического уклада во второй половине XVII в. на всей обширной территории Центральной Азии коснулись и Тибетского государства. Оно также переживало существенные изменения политико-административной структуры. Этот период стал временем естественного процесса раздела власти и влияния между претендентами на власть в Тибете, сопровождавшегося идеологическим противостоянием и открытыми вооруженными конфликтами.

Продолжительная борьба между религиозными школами шла также по линии богословской и религиозно-философской. Противники часто выступали с взаимной критикой религиозно-философских взглядов, вступая в открытые диспуты, что отражалось и в их сочинениях. В каждой буддийской школе создавались сиддханты, отличавшиеся своей разновидностью, систематизацией, структурированием и классификацией школ. Прежде всего, сиддханты были ориентированы на задачи изложения и сравнительного анализа небуддийских и буддийских религиозно-философских систем, сформировавшихся в Древней Индии, и максимально приближенно перенесенных на тибетскую почву. Очевидно, что сиддханта в Тибете применялась преимущественно для описания всех направлений индийского буддизма.

Наибольший вклад в развитие этого жанра внесли гелугпинские ученые-ла- мы под влиянием историко-философского труда Кунчена Жамьяна Шадпы Дорже (1648-1722) под названием «Grubmtha'i-rnam-bshad-rang-gzhan-grubmtha'-kun-dang-zab-don-mchog-tu-gsalba-kun-bzang-zhing-gi-nyi-ma-lung-rigsrgya-mtsho-skye-dgu'i-re-ba-kun-skong») («Солнце, в совершенстве проясняющее глубинный смысл положений философских школ - как буддийских, так и небуддийских. Океан писания и логики суждений, исполняющий все надежды живых существ»), более известного под кратким названием «Grub-mtha' chen-mo» («Дубта ченпо»).

Также большой интерес вызывают «Grub-pa'i-mtha'i-rnam-par-bzhag-pa-rinpo-che‘i-phreng-ba» («Презентация философских систем: “Драгоценная гирлянда"») Гончога Чжигме Ванбо (II Жамьян Шадпа, 1728-1791); «Grub-mtha'-thamscad-kyi-knungs-dang-_dod-tshul-stan-palegs-bshad-shel-gyi-me-long» («Основа всех сиддхант - хороший трактат - Хрустальное зерцало, показывающий правила изложения /взглядов/») Тугана Лобсана Чойжи Нимы (1737-1802); «Grubmtha'-rtsa-ba'i-tshig-ti-ka-shel-dkar-melong» («Подстрочный комментарий к "Коренному трактату по философским системам" [Жамьяна Шадпы]: "Хрустальное зерцало”») Лобсана Кончога (1742-1822).

Среди наиболее известных монгольских трудов этого жанра - первое крупное исследование в Монголии «Tsadma-sde-bdun-gyi-snyin-nor-dang / Grubmtha'-i rnam-bzhag-nyung-'dus» («Краткое обозрение различий философских взглядов») [Collected works... 1975] Сумбакхамбо Ешей-Балджора (1704-1788); одно из самых известных трудов «Grubpa'i-mtha'i-rnam-par-bzhag-pa-gsal-barbshad-pa-thub-bstan-1hun-po'i-mdzesrgyan» («Ясное разъяснение положений философских школ, называемое - Украшение чаши Учения Будды») принадлежит Чжанже Ролби Дорже (1717-1786); комментарий «Абхидхармакоши» под названием «Chos-mngon-pa'I-mdzod-kyidog-sdpyod-blo-gsar-rol-rtsad» («Кладезь 
счастья для определенных мудрецов, объясняющий некоторые вопросы высочайшей Абхидхармакоши»), «Grubmtha'-bzhi'i-lugs-kyi-kun-rdzob-dangdon-dam-pa'i-don-rnam-par-bshad-pa-legsbshad-dpyid-kyi-dpal-mo'i-glud-byangs» («Объяснение конвенциональной и окончательной истин в четырех философских системах: "Песнь прекрасных объяснений весенней кукушки”»), а также комментарий «Grub-mtha'I-chen-mo'Imchan-grel-bka'-gnad-mdud-grol-blo-gsalgces-nor-zhes-bya-ba-bzhugs-so» («Достояние просветленных учеников, развязывающих трудный узел смысла комментариев философских взглядов») к «Grubmtha' chen-mo» («Дубта ченпо») Кунчена Жамьяна Шадпы Дорже, автором которых является Агван Балдан (1797-1864); «Драгоценные четки, /повествующие/ в стихах сиддханту» Ешей-Цэринжаба; «Grub-mtha'i-tshing-bcad-rin-chen-'phrenba» («Драгоценные четки - сущность пяти частей астрологии») Ригцзина Цэбжида Дорчже (XIX в.); «Grub-mtha'i-rtsiskyi-yan-lag-lngab-sdus-kyi-rnam-bzhagnor-bu-'phreng-ba» («Комментарии на основные понятия сиддханты») ханчингабчжу Лобсана Дорчже (род. в 1790 г.) из Сайнхановского аймака; Grub-mtha'irtsa-ba'i-tshing-'grel» («Критический разбор философских взглядов»), «Grubmtha'i-dogs-slong» («Комментарии по основам взглядов разных школ») Лобсана Чойдана и др.

Несмотря на изобилие исследований данного жанра, труд Кунчена Жамьяна Шадпы представляет особую научную ценность для исследования древнеиндийской религиозно-философской мысли и тибетской традиции буддизма в научных кругах в области востоковедения, буддологии, тибетологии, источниковедения, религиоведения, и мы считаем целесообразным отразить преломление индийской традиции и развитие буддийской философской мысли в Тибете на основе данного источника.

Сиддханта Жамьяна Шадпы основывается на колоссальном материале ранних источников, емко отражая все многообразие взглядов и подходов древнеиндийских авторов по конкретной тематике. Сам автор отмечает в «Grubmtha' chen-mo» («Дубта ченпо»), что это исследование изложено на основе санскритских буддийских и небуддийских источников, которые ранее в философских школах Тибета не использовались. Он пишет: «Такого подробного изложения различий "Великих путей” и глубокого учения "шуньи" ранее не было сделано ни в Индии, ни в Тибете» [Кунчен Жамьян Шадпа Дорже 1999: 643].

Описывая «Grub-mtha“ chen-mo» («Дубта ченпо») Кунчена Жамьяна Шадпы, Дж. Хопкинс также подчеркивает изобилие цитат индийских источников в тексте и отмечает лаконичность стиля изложения и служит в качестве упрощенной методики запоминания принципов системы догм [Hopkins 2003: 4]. Распутывая одни вопросы и предлагая другие, он создал монументальный по величине труд, пронизанный в значительной степени источниками цитирования.

Итак, сиддханта «Дубта ченпо» состоит из трех глав: первая глава представляет собой вводную часть, в которой автором дается общее описание небуддийских и буддийских школ, являющееся общим конспектом содержания всего сочинения. Вторая глава посвящена истории философии, в которой содержится трактовка небуддийских и буддийских систем. В трактате упоминается 570 небуддийских школ. Исключением стала система Бон-по, которая, по мнению автора, не представляет философского учения [Кунчен Жамьян Шадпа Дорже 1999: 59-184]. Описывая небуддийские школы, Жамьян Шадпа сделал акцент на основные идеи, уставы и труды, в которых представлены их мировоззренческие взгляды.

Буддийская традиция в основной части сиддханты представлена двумя хинаянскими школами и их подшколами (I-II), а также махаянской системой йогачара (III):

I. «Bye-brag-smra-ba» («Вайбхашика») и еe 18 подшкол. 
II. «Mdo-sde-pa» («Саутрантика»):

1) «Lung-gi-rjes-'brangs-mdo-sde-pa» («Саутрантики, следующие священнописанию»);

2) «Rigs-pa'i-rjes-'brangs -mdo-sde-pa» («Саутрантики, следующие логической apгументации»).

III. «Sems-tsam-pa» («Йогачара»):

1) «Lung-gi-rjes-'brangs» («Йогачары, следующие священнописанию»);

2) «Rigs-pa'i-rjes-'brangs» («Йогачары, следующие аргументации»).

Согласно Дж. Хопкинсу, в «Grubmtha" chen-mo» («Дубта ченпо») Жамьян Шадпа указал принципы, которые свойственны каждой из 18 школ, в соответствии с трактатом Васубандху «Абхидхармакоша». Автор раскрывает множество различных взглядов в целях отражения диапазона перспектив и отклонения двусмысленностей, возникающих на основе кратких представлений. Мы согласны с мнением Дж. Хопкинса, что объединение всех 18 школ в одну является своего рода необходимостью, поскольку их религиозно-философские взгляды настолько различны, что трудно назвать принципы, характерные для всех этих школ [Hopkins 2003: 10].

При изучении индийских источников, касающихся взглядов представителей школы саутрантика, тибетские мыслители разных школ неоднозначно интерпретировали их идеи. Гелугпинцы разработали особую классификацию школы саутрантика в целях более доступного понимания их учения, разделив саутрантиков на две подшколы. Согласно Кунчену Жамьяну Шадпе, это было сделано для удобства анализа воззрений саутрантиков, поскольку гораздо сложнее выделить общие признаки, достаточные для объединения их в одну школу [Кунчен Жамьян Шадпа Дорже 1999: 245]. В «Абхидхармакоше» Васубандху говорится, что «Lung-gi-rjes-'brangs-mdo-sde-pa» («саутрантики, следующие священнописанию») опираются на сочинения в основном Асанги и его сводного брата Васубандху. «Rigs-pa'i-rjes-'brangs-mdosde-pa» («саутрантики, следующие аргу- ментации»), в отличие от вайбхашиков, которые следуют коренному трактату «Махавибхаше», являются последователями Дигнаги и Дхармакирти. Они утверждают существование внешних объектов, которые отличны от объектов, воспринимаемых сознанием. B «Grubmtha' chen-mo» («Дубта ченпо») Кунчен Жамьян Шадпа отмечает, что ни одна из этих подшкол не видела более мощной школы, кроме школы саутрантика [Кунчен Жамьян Шадпа Дорже 1999: 245]. В целом стоит отметить, что в традиции Гелугпа особенностью изучения воззрений саутрантики является то, что они рассматриваются в рамках педагогической целесообразности. Так, А. К. Кляйн убеждена, что понимание пустотности или бессущности, как это понимается в гелугпинском представлении индийской мадхьямаки, возможно на основе понимания саутрантиковской «самости» как абсолютной истины, которая отрицается теорией бессущности мадхьямики [Кляйн 2009; Klein 1986: 15].

Далее, презентуя краткий обзор содержания сиддханты Кунчена Жамьяна Шадпы, акцентируем внимание на новационном подходе автора к изложению религиозно-философских взглядов школы йогачара. В своей сиддханте он изложил взгляды этой махаянистической системы в одной главе с философскими школами Хинаяны вайбхашика и саутрантика. В этой связи мы наблюдаем особую оригинальность структуры исследуемого сочинения, поскольку подобное объединение систем разных буддийских толков не свойственно тибетским авторам этого жанра. На первый взгляд, такой подход кажется довольно странным, т. к. эта глава посвящена преимущественно школам Хинаяны, а йогачары являются яркими представителями махаянского толка. Однако проанализировав содержание «Grub-mtha' chen-mo» («Дубта ченпо») и учитывая религиознофилософские и политические приоритеты Кунчена Жамьяна Шадпы, его решение считается вполне закономерным.

Во-первых, этим структурным подходом Кунчен Жамьян Шадпа, вероятно, 
хотел подчеркнуть влияние абхидхармического учения не только на хинаянские системы, но и на махаянские. Так, воззрения ранней йогачары, основанной Асангой в IV-V вв. н. э., основаны на преобразованной махаянической теории Абхидхармы Арьясанги, главной особенностью которой было увеличение числа дхарм до 100, в отличие от прежних 75.

Во-вторых, решение автора об отражении религиозно-философских воззрений йогачаров отдельно от махаянской системы мадхьямика, на наш взгляд, не лишено логики, поскольку в данной сиддханте учение йогачаров выступало в качестве связующего звена в непрерывно развивающемся потоке буддийской религиозно-философской мысли, призванного создать необходимую доктринальную платформу для восприятия наиболее сложного и в то же время наивысшего буддийского учения - Праджняпарамиты. В этой связи учение системы мадхьямика было выделено им в отдельную объемную главу, в которой особое внимание автором уделено мадхьямике-прасангике, сыгравшей значительную роль в становлении и развитии праджняпарамитской мысли.

Кунчен Жамьян Шадпа акцентировал внимание на разъяснении Пути самосовершенствования, которое принадлежит школе Кадампа, созданной Атишей, впоследствии развитое в системе Ламрим Цзонхавой. Кунчен Жамьян Шадпа в своем исследовании сделал значительный акцент на разъяснении данной методики, дав ее развернутую презентацию.

Путь подготовки - это лишь начало на Пути самосовершенствования, раскрытого Цзонхавой в системе «Ламрим». В связи с тем что данная система получила широкое развитие в рамках праджняпарамитской мысли традиции гелугпа, в частности школы мадхьямикапрасангика, Кунчен Жамьян Шадпа, будучи ее ярким представителем, раскрыл дальнейшую суть Пути в заключительной главе сиддханты, посвященной учению системы мадхьямика, таким образом плавно подготавливая к восприятию учения о Праджняпарамите. По мнению Кунчена Жамьяна Шадпы, как и многих последователей Цзонхавы (1357-1419), в лице приверженцев йогачары представлен компромиссный вариант учения об отсутствии «я» для тех, кому воззрения сутр Праджняпарамиты оказались слишком радикальны и сложны для понимания. Одним из существенных элементов этого учения является доктрина татхагатагарбхи. Это положение лежит в основе теоретического обоснования образовательной системы гелугпинских монастырей, получившей широкое распространение и за пределами Тибета.

Говоря о системе йогачара, Кунчен Жамьян Шадпа показал, что она стала своеобразным мостом между абхидхармическим учением раннебуддийских школ и праджняпарамитской философией самой сложной и «высокой» буддийской школы мадхьямики-прасангики. Поскольку учение йогачаров, во-первых, является воплощением махаянской абхидхармы, опирающейся на трактат «Абхидхармасамуччая» Асанги, а во-вторых, представляет собой новую систему сотериологических подходов, представленных в сутрах Праджняпарамиты. Таким образом, в «Grub-mtha' chen-mо» [«Дубта ченпо»] Кунчен Жамьян Шадпа доказал, что учение школы йогачара представляет собой органическое развитие буддийской мысли, непротиворечивое в философском плане и дополняющее в сотериологическом смысле, акцентирующее внимание, прежде всего, на методах освобождения от сансары.

B «Grub-mtha' chen-mo» [«Дубта ченпо»] Кунчен Жамьян Шадпа ювелирно очертил линию преемственности религиозно-философской мысли, согласно которой восприятие четырех философских школ (тиб. Grub-mtha'-bzhi) должно осуществляться как единая иерархизированная система познания абсолютной природы реальности, в которой каждая из них служит ступенью для понимания воззрения следующей, более высокой школы, а также организации махаянских практик в системе, в которой они частич- 
но совпадают с хинаянскими, и в именовании этой совместной части «общими» (тиб. Thun-mong) этапами пути. Эта индо-тибетская система философии и медитации, для которой характерно единство Хинаяны и Махаяны, как путь парамитаяны называется Ламрим, а как путь ваджраяны - Нгагрим, базируется на парадигмальных положениях, обоснованных учеными Наланды. Так, махаянские учения о пустоте (Нагарджуны) и учения о пути бодхисаттв (Асанги), изначально передаваемые по двум разным линиям преемственности, соединились в одном реализованном учителе - Атише [Урбанаева 2014: 344], который, объединив эти две линии преемственности, передал их в Тибете, где они продолжились в виде традиции Ламрим, успешно развитые основателем традиции гелугпа Цзонхавой и его последователями, в частности Кунченом Жамьяном Шадпой.

Кунчен Жамьян Шадпа оказал сильнейшее влияние на развитие историкофилософского жанра сиддханта в Тибете. Принципы изложения материала, привнесенные Жамьяном Шадпой в его трактаты, стали впоследствии приме- няться во всех гелугпинских сочинениях этого жанра. В свою очередь, подчеркнем, что жанр сиддханта стал мощным инструментом в распространении буддийского учения в Тибете и на территории Центральной Азии.

Как показал анализ, приведенный в данной статье, в структуре сиддхант, содержании, языке и тематическом анализе школ емко отражаются возможности буддийской диалектики, которые характеризуются влиянием буддийской теории аргументации и логико-эпистемологической традиции Тибета, отражающейся в монастырской системе образования. В этой связи вполне закономерно применение сиддханта в образовательной системе монастырей. Сиддханта признаются ценным практическим пособием по буддийскому диспуту в монастырских университетах. Интеграция в систему образования гелугпинских монастырей жанра сиддханта придала значительный импульс дальнейшему развитию, распространению и ускоренению буддийского учения традиции гелугпа не только на территории Тибета, но и во всем Центрально-Азиатском регионе.

Статья подготовлена при финансовой поддержке Российского научного фонда в рамках научно-исследовательского проекта «Буддизм в сочиально-политических и культурных процессах России, Внутренней и Восточной Азии: трансформащии и перспективы», № 14$18-00444$.

\section{Питература}

Васильев В. П. Буддизм, его догматы, история и литература. Ч. 1 / В. П. Васильев. - СПб., 1869. $-353 \mathrm{c}$.

Востриков А. И. Тибетская историческая литература / А. И. Востриков. - М.: Восточная литература, 1962. - 428 с.

Гулгенова А. Ц. Кунчен Жамьян Шадпа Дорже (1648-1722) в истории религиозно-философской мысли тибетского буддизма / А. Ц. Гулгенова; отв. ред. Л. Е. Янгутов. - Улан-Удэ: Изд-во Бурятского госуниверситета, 2016. - 276 с.

Гулгенова А. Ц. Религиозно-философские воззрения вайбхашиков в творчестве Кунчен Жамьян Шадпа Дорже (1648-1722) / А. Ц. Гулгенова; отв. ред. Л. Е. Янгутов. - Улан-Удэ: Изд-во Бурятского гос. ун-та, 2015. - 166 с.

Кляйн А. Знание и освобождение. Тибетская буддийская эпистемология, обосновывающая трансформацию религиозного переживания / А. Кляйн; пер. Д. Устьянцев; ред. А. Орлов. - М.: Шечен, 2009. - 256 с.

Кунчен Жамьян Шадпа Дорже [тиб. Kun-mgyen-‘jam-dbyangs-bshad-pa-rdo-rje). Grubmtha'i-rnam-bshad-rang-gzhan-grub-mtha'-kun-dang-zab-don-mchog-tu-gsal-ba-kun-bzang-zhing-gi-nyi-ma-lung-rigs-rgya-mtsho-skye-dgu'i-re-ba-kun-skong]. [Солнце, в совершенстве про- 
ясняющее глубинный смысл положений философских школ, как буддийских, так и небуддийских. Океан писания и логики суждений, исполняющий все надежды живых существ]. - Mundgod, India: Drepung Gomang Library, Lama Camp., 1999. - 1020 p.

Нестеркин С. П. Историко-философская традиция тибетского буддизма / С. П. Нестеркин // Вестник Бурятского научного центра СО РАН. - 2014. - № 4(16). - С. 10-17.

Островская Е. А. Тибетский буддизм / Е. А. Островская. - СПб.: Петербургское востоковедение, 2002. - 400 с.

Пубаев Р. Е. История буддийской сиддханты в освещении Сумба-Хамбо в сочинении «Пагсам-Чжонсан» / Р. Е. Пубаев // Буддизм и средневековая культура народов Центральной Азии. - Новосибирск: Наука, 1980. - С. 40-54.

Урбанаева И. С. Буддийская философия и медитация в компаративистском контексте (на основе индо-тибетских текстов и живой традиции тибетского буддизма) / И. С. Урбанаева. Улан-Удэ: Изд-во ИМБТ СО РАН, 2014. - 376 с.

Хадалов П. И. Описание сочинений Гучен-Чжамьян-Шадпа-Дорчже / П. И. Хадалов, Л. Ж. Ямпилов, Б. Д. Дандарон. - Улан-Удэ: Изд-во БКНИИ СО АН, 1962. - 126 с.

Хундаев В. Ю. История тибетской религиозно-философской литературы Сиддханта: анализ генезиса и развития / В. Ю. Хундаев // Вестник Бурятского гос. ун-та. - 2009. - № 8. - C. 78-84.

Чже Цонкапа. Большое руководство к этапам Пути Пробуждения. Т. 1 / пер. с тиб. А. Кугявичус; под общ. ред. А. Терентьева. - СПб.: Нартанг, 1994. - 446 с.

Collected works of Sumpa-mkanpo. Reproduced by Lokesh Chandra. Vol. Kha (2) / Sata-pitaka series. - New Delhi, 1975. - P. 29-65.

Cozort D., Preston G. Buddist philosophy: Losang Gonchok's short commentary to Jamyang Shayba's Root text on tenets. - NY: Snow Lion Publications, 2004. - 352 p.

Hopkins P. J. Maps of the profound (Jam-yang-Shay-ba's Great exposition of Buddhist and Non-buddhist views on the Nature of reality) / P. J. Hopkins. - Itaka; New York, 2003. - 1135 p.

Jackson D. P. Two grub mtha' treaties of Sa-skya Pandita - one lost and one forged / D. P. Jackson // The Tibet journal. - Vol. 10. - 1985. - No. 1.

Katsumi Mimaki. Blo-gsa- grub-mtha': chapitres IX (Vaibhasika) et XI (Yogacara) et chapitre XII (Madhyamika). - Kyoto: Zinbun Kagaku Kenkyusyo, Universite de Kyoto, 1982. - 328 p.

Klein A. C. Knowledge and liberation. Tibetan Buddhist epistemology in support of transformative religious experience / A. C. Klein. - Itaka; New York: Snow Lion Publications, 1986. - 256 p.

Tibetan literature studies in genre / ed. by Jose Ignacio Cabezon, Roger R. Jackson. - Ithaca, New York: Snow Lion Publications, 1996. - 552 p.

\section{References}

Vasilev V. P. Buddizm, ego dogmatyi, istoriya i literatura / V. P. Vasilev. - Sankt-Peterburg, 1869. - Ch. 1. $-353 \mathrm{~s}$.

Vostrikov A. I. Tibetskaya istoricheskaya literatura. - M.: Vostochnaya literatura, 1962. $-428 \mathrm{~s}$.

Gulgenova A. Ts. Kunchen Zhamyan Shadpa Dorzhe (1648-1722) v istorii religiozno-filosofskoy myisli tibetskogo buddizma / Otv. red. L. E. Yangutov. - Ulan-Ude: Izd-vo Buryatskogo gosuniversiteta, 2016. $-276 \mathrm{~s}$.

Gulgenova $A$. Ts. Religiozno-filosofskie vozzreniya vaybhashikov v tvorchestve Kunchen Zhamyan Shadpa Dorzhe (1648-1722) / A. Ts. Gulgenova; Otv. red. L. E. Yangutov. - Ulan-Ude: Izd-vo Buryatskogo gos. Un-ta, 2015. - 166 s.

Klyayn A. Znanie i osvobozhdenie. Tibetskaya buddiyskaya epistemologiya, obosnovyivayuschaya transformatsiyu religioznogo perezhivaniya / per. D. Ustyantsev; red. A. Orlov. - Moskva: Shechen, 2009. - $256 \mathrm{~s}$.

Kunchen Zhamyan Shadpa Dorzhe [tib. Kun-mgyen-'jam-dbyangs-bshad-pa-rdo-rje). Grubmtha'i-rnam-bshad-rang-gzhan-grub-mtha'-kun-dang-zab-don-mchog-tu-gsal-ba-kun-bzangzhing-gi-nyi-ma-lung-rigs-rgya-mtsho-skye-dgu'i-re-ba-kun-skong]. [Solntse, $\mathrm{v}$ sovershenstve proyasnyayuschee glubinnyiy smyisl polozheniy filosofskih shkol kak buddiyskih, tak i nebuddiyskih. Okean pisaniya i logiki suzhdeniy, ispolnyayuschiy vse nadezhdyi zhivyih suschestv]. Mundgod, India: Drepung Gomang Library, Lama Camp., 1999. - 1020 p. 
Nesterkin S. P. Istoriko-filosofskaya traditsiya tibetskogo buddizma / S. P. Nesterkin // Vestnik BNTs SO RAN, \#4 (16), 2014. - S. 10-17.

Ostrovskaya E. A. Tibetskiy buddizm / E. A. Ostrovskaya. - Sankt-Peterburg: Peterburgskoe vostokovedenie, 2002. $-400 \mathrm{~s}$.

Pubaev R. E. Istoriya buddiyskoy siddhantyi v osveschenii Sumba-Hambo v sochinenii «Pagsam-Chzhonsan» / R. E. Pubaev // Buddizm i srednevekovaya kultura narodov Tsentralnoy Azii. - Novosibirsk: Nauka, 1980. - S. 40-54.

Urbanaeva I. S. Buddiyskaya filosofiya i meditatsiya v komparativistskom kontekste (na osnove indo-tibetskih tekstov i zhivoy traditsii tibetskogo buddizma) / I. S. Urbanaeva. - Ulan-Ude: Izd-vo IMBT SO RAN, 2014. - 376 c.

Hadalov P. I. Opisanie sochineniy Guchen-Chzhamyan-Shadpa-Dorchzhe / P. I. Hadalov, L. Zh. Yampilov, B. D. Dandaron. - Ulan-Ude: Izd-vo BKNII SO AN, 1962. - 126 s.

Hundaev $V$. Yu. Istoriya tibetskoy religiozno-filosofskoy literaturyi Siddhanta: analiz genezisa i razvitiya / V. Yu. Hundaev // Vestnik Buryatskogo gos. un.-ta. - 2009. - \# 8. - S. 78-84.

Chzhe Tsonkapa. Bolshoe rukovodstvo k etapam Puti Probuzhdeniya. T. 1 / per. s tibet. A. Kugyavichus ; pod obsch. red. A. Terenteva. - Sankt-Peterburg: Nartang, 1994. - 446 s.

Collected works of Sumpa-mkanpo. Reproduced by Lokesh Chandra. Vol. Kha (2) / Sata-pitaka series. - New Delhi, 1975. - S. 29-65.

Cozort D., Preston G. Buddist philosophy: Losang Gonchok's short commentary to Jamyang Shayba's Root text on tenets. - NY: Snow Lion Publications, 2004. - $352 \mathrm{~s}$.

Hopkins P. J. Maps of the profound (Jam-yang-Shay-ba's Great exposition of Buddhist and Non-buddhist views on the Nature of reality) / P. J. Hopkins. - Itaka; New York, 2003. - 1135 s.

Jackson D. P. Two grub mtha' treaties of Sa-skya Pandita - one lost and one forged // The Tibet journal. - Vol. 10. - No. 1. - 1985.

Katsumi Mimaki. Blo-gsa- grub-mtha': chapitres IX (Vaibhasika) et XI (Yogacara) et chapitre XII (Madhyamika). - Kyoto: Zinbun Kagaku Kenkyusyo, Universite de Kyoto, 1982. - 328 s.

Klein A. C. Knowledge and liberation. Tibetan Buddhist epistemology in support of transformative religious experience / A. C. Klein. - Itaka; New York: Snow Lion Publications, 1986. - 256 s.

Tibetan literature studies in genre / ed. by Jose Ignacio Cabezon, Roger R. Jackson. - Ithaca, New York: Snow Lion Publications, 1996. - 552 s. 